\title{
NEW TECHNOLOGIES OF WATER TREATMENT AT HEAT POWER PLANTS
}

\author{
Mukhabbat Asretdinova ${ }^{1}$ \\ ${ }^{1}$ Tashkent state technical University named after Islam Karimov, University- 1, Tashkent, 100095, Uzbekistan
}

\begin{abstract}
The main objective of water treatment in the energy sector is the desalination of water. Since, calcium and magnesium compounds are those that can reduce the service life of heating elements of energy enterprises by several times.
\end{abstract}

\section{Introduction}

The main objective of water treatment in the energy sector is the desalination of water. Since, calcium and magnesium compounds are those that can reduce the service life of heating elements of energy enterprises by several times. Water treatment and water purification systems are the most important component of the equipment of energy enterprises. It is the quality of the source water that directly affects not only the reliability and efficiency of the entire energy complex, but also the period of replacement of pipes affected by corrosion or iron oxide deposits.

\section{Energy facilities include:}

- boiler stations,

- separate industrial water heating plants,

- CHP and TPP

- pipelines

\section{Sources of water supply in the energy sector}

As a source of water supply for boiler stations, CHP and TPP can use an artesian well, surface water or city water supply (if the facility is located within the city).

When connecting the water supply system of an energy enterprise to the existing communications, the filter is determined by the requirements of the documentation $(1,2)$. Water from an artesian well or a lake is preliminary purified in "sedimentation tanks" and "mud collectors".

\section{The tasks of water filters in the energy complex}

Equipment for water treatment in the energy complex is used to trap colloidal and coarse impurities, as well as saltforming elements. However, in reality, filters for boiler plants, CHP and TPP have much more functions (Table $1)$.
Table 1. Functions of water treatment systems in the power industry

\begin{tabular}{|c|c|}
\hline $\begin{array}{c}\text { Power } \\
\text { equipment type }\end{array}$ & Filtration system tasks \\
\hline Boiler rooms & $\begin{array}{l}\text { - optimization of } \mathrm{pH} \text { of steam, } \\
\text { water and condensate; } \\
\text { - prevention of salt formation } \\
\text { on the surface of boilers and } \\
\text { pipelines; } \\
\text { - apturing corrosive gases; } \\
\text { - water softening; } \\
\text { - optimization of the chemical } \\
\text { composition of the thermal } \\
\text { agent. }\end{array}$ \\
\hline $\begin{array}{l}\text { District heating } \\
\text { systems (CHP) }\end{array}$ & $\begin{array}{l}\text { - reduction of corrosion; } \\
\text { - pH optimization; } \\
\text { - corrosion protection of } \\
\text { copper, bronze and aluminum } \\
\text { equipment elements; } \\
\text { - deaeration of water. }\end{array}$ \\
\hline $\begin{array}{c}\text { Circulating } \\
\text { cooling systems }\end{array}$ & $\begin{array}{l}\text { - preventing the development of } \\
\text { corrosion processes; } \\
\text { - prevention of pipeline } \\
\text { biofouling; } \\
\text { - prevention of the formation of } \\
\text { salt deposits on the inner } \\
\text { surfaces of the equipment; } \\
\text { - treatment of cooling water at } \\
\text { nuclear power plants and } \\
\text { thermal power plants. }\end{array}$ \\
\hline
\end{tabular}




\section{Filtration equipment - protection against heat loss}

When "raw" water is used in power engineering, a thick sedimentary layer of magnesium and calcium salts forms on the heating elements. Such a \&quot;pillow\&quot; is a good heat insulator, due to which the heat consumption increases significantly. Iron compounds also differ in their ability to accumulate thermal energy. That is why desalination of water in the power industry is one of the main stages of organizing the work of an enterprise.

According to research, the heat transfer of heating elements affected by salt deposits is reduced by $20-40 \%$. In addition, the efficiency of the equipment also drops significantly, which leads to breakdowns and causes premature repairs.

The productivity of equipment for water filtration in the power industry can reach 900 cubic meters per hour. At the same time, regular regeneration of highperformance water treatment systems is invariably associated with the need to purify and dispose of wastewater and waste from an energy company.

In the last decade, both the construction of new and extensive reconstruction of existing water treatment plants (WTP) have been carried out. The main method currently used for desalination at most thermal and ion exchange filters and installations based on membrane methods are being used.

Some new WTPs are based on the use of reverse osmosis for water demineralization using traditional technologies (clarifiers) as pretreatment. (fig. 1). The use of reverse osmosis makes it possible to extract up to 96$98 \%$ of salts at one stage of purification, which is close to the efficiency of one stage of ion exchange [2]

The ion-exchange post-treatment system can consist of an ion exchange stage with one cation and one anion exchange filter, and / or a mixed-bed filter. Since demineralized water is supplied to such an installation, the filter resource is enormous, reaching tens and hundreds of thousands of cubic meters.

demineralization by ion exchange and reverse osmosis showed [1] that with a salt content of more than 150-300 $\mathrm{mg} / \mathrm{l}$, reverse osmosis is more economical even than countercurrent ion exchange. However, experience shows that in such schemes the quality of the source water of the UOO often does not meet the requirements for the iron content and oxidizability [1]. A solution to this can be achieved by using ultrafiltration at the pre-treatment stage.

Ultrafiltration makes it possible not only to obtain water practically free from mechanical impurities, but also, together with coagulation, to remove a significant

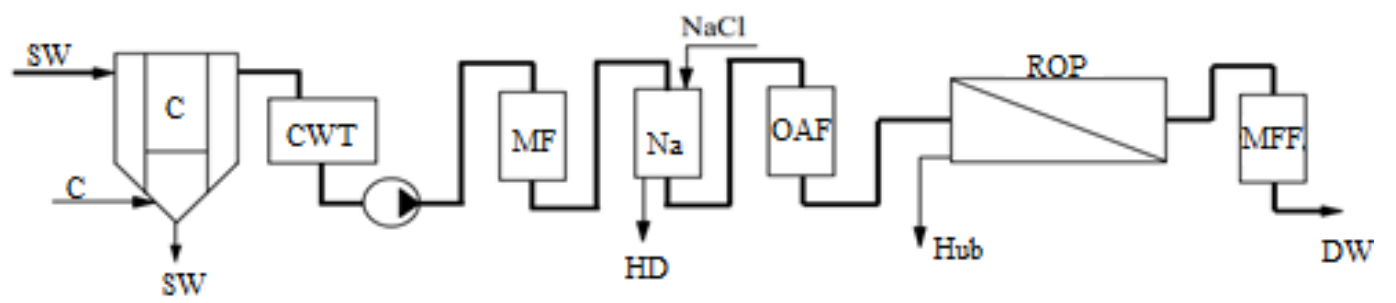

Fig. 1. Scheme of the WTP: SW - source water; C - clarifier; CWT - clarified water tank; MFF mechanical filter; $\mathrm{Na}$ - Na-cationic filter; OAF - organic absorber filter; $\mathrm{C}$ - coagulant; SW - sludge water; DW - demineralized water

nuclear power plants is ion exchange. The disadvantages of this technology include: a significant amount of necessary water treatment equipment, a high need for acid and alkali, which leads to the need for a rather complex reagent economy, a system for neutralizing wastewater and the formation of highly mineralized wastewater, the discharge of which is limited. Moreover, the consumption of reagents for regeneration, as a rule, is 2-3 times higher than the stoichiometric one. Accordingly, the amount of dumped salts increases by the same number of times. As a result, all this leads to high capital and operating costs.

Due to the unpredictable selectivity of ion-exchange materials in relation to organic pollution, the total organic carbon in demineralized water can be in the range from 100 to $500-800 \mu \mathrm{g} / 1$, which does not meet modern requirements. Even the use of organo-absorbing ion exchangers in most cases does not lead to the achievement of the required indicators, but increases the water consumption for own needs and the consumption of sodium chloride and alkali for regeneration.

In order to reduce the operating costs of water treatment, improve the quality of demineralized water, new technologies for water treatment on countercurrent amount of organic matter (up to $60 \%$ of the initial amount), as well as colloidal silicic acid.

The combined use of ultrafiltration and reverse osmosis makes it possible to create a low-reagent water treatment system for obtaining a filtrate with a specific electrical conductivity of 1-5 $\mu \mathrm{S} / \mathrm{cm}$. In such schemes, further bringing the water quality up to the standard values 
is carried out by ion exchange (Fig. 2) or electroionite [3] (Fig. 3) methods. degassing and electrodeionization, called as a whole integrated membrane technologies (IMT) [3].

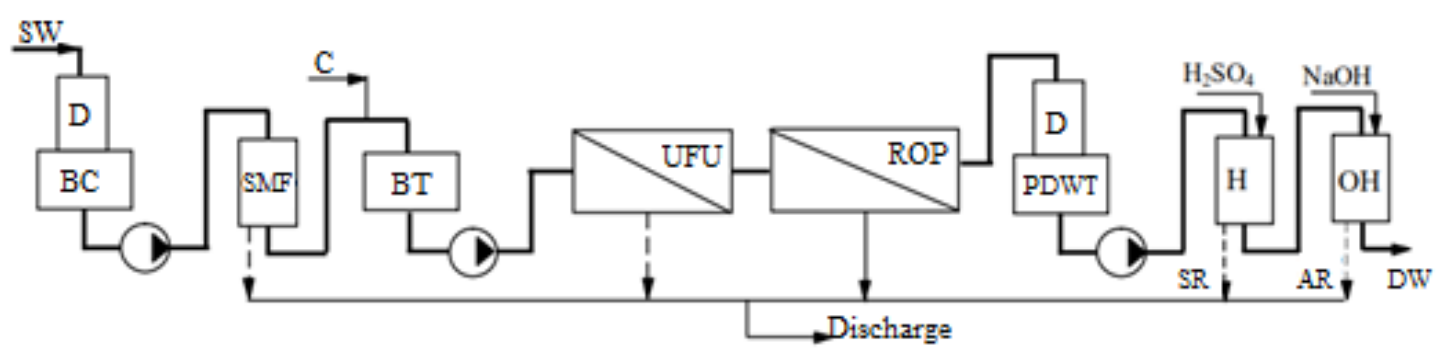

Fig. 2. Scheme of a combined installation for the preparation of deeply demineralized water using ion-exchange post-treatment:

The reliability of the combined membrane-ion exchange plant (Fig. 2) is high, since even in case of possible malfunctions of the reverse osmosis system, the post-treatment unit will provide the specified water quality. At the same time, there is still a need to use acid and alkali, so this technology, albeit to a lesser extent, has the same disadvantages as the traditional one.

The main disadvantage of all membrane systems is a rather low coefficient of use of source water. If in the traditional ion-exchange scheme with coagulation and mechanical filtration at the outlet, a productivity of 85 $90 \%$ of the flow rate of the source water is achieved, then for a typical combination of ultrafiltration and reverse osmosis this figure does not exceed $50-60 \%$. However, it should be borne in mind that concentrates from ultrafiltration and reverse osmosis plants in terms of salinity are often within the normalized values and can be freely discharged.

Combined membrane-ion-exchange schemes, which have a high degree of economic efficiency and reliability,
In a complex membrane unit (Fig. 3), water is further purified at the electrodeionization unit. Electrodeionization (EDI) is a process of continuous desalination of water using ion exchange resins, ionselective membranes and a constant electric field [3]. The electrodeionization module contains two electrodes, the space between which is filled with thin layers of ionexchange resins, separated by ion-selective membranes. Such membranes are a finely ground cation resin or anion resin sintered with polyethylene into a thin film.

With the degree of use of source water $90-95 \%$, purified water has a specific electrical conductivity of $0.07 \mu \mathrm{S} / \mathrm{cm}$, as well as the minimum content of silicon and total organic carbon. In this case, the salinity of the concentrate is usually lower than the salinity of the water supplied to the reverse osmosis unit, so it is all returned to the input of this unit for reuse.

To improve the reliability of complex membrane water treatment systems based on BMI, it is required to use two-stage reverse osmosis at the stage of preliminary

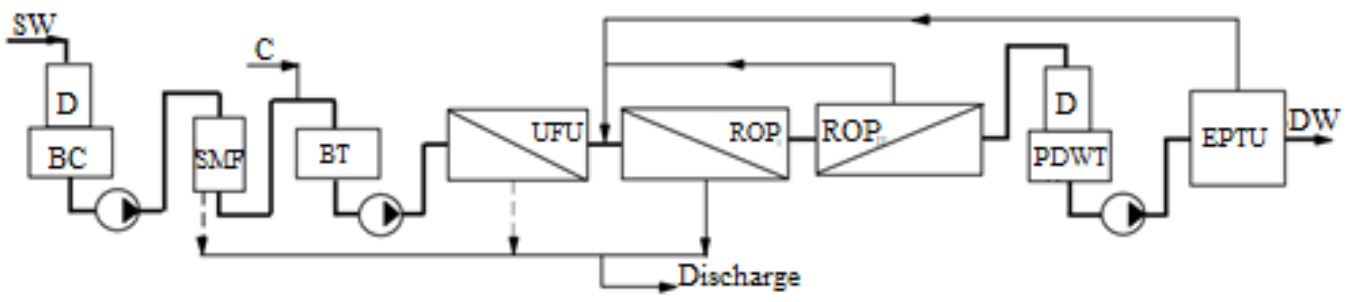

Fig. 3. Scheme of a complex installation for the preparation of deeply demineralized water with the use of post-treatment by electrodeionization: PTEI - post-treatment unit by electrodeionization

are the optimal and recommended method for the reconstruction of existing WTPs, which already have ionexchange filters, reagent facilities and waste collection and neutralization systems. The amount of concentrated wastewater and the consumption of reagents in this case are tens of times less than with a purely ion-exchange scheme. The resulting regenerates can be diluted to acceptable standards with the concentrate of membrane units.

From the point of view of ensuring the minimum consumption of reagents and the highest environmental friendliness with the high quality of demineralized water, the most effective are complex WPUs, consisting exclusively of membrane modules for various purposes: ultra- and nano-filtration, reverse osmosis, membrane desalination (Fig. 3).A complex membrane installation for the preparation of deeply demineralized water, made in accordance with this scheme, provides a minimum volume of waste. There is no need for an acid-alkali economy, operating costs are reduced and environmental parameters are dramatically improved. The cost of an electro-deionization installation is less than that of an ionexchange one, and taking into account the cost of an acidreagent facility, it is much less.

\section{Conclusion}

Thus, the introduction of new desalination technologies in the heat power industry and at enterprises of Uzbekistan, where high-quality water is required, will significantly 
reduce production costs due to a multiple reduction in the consumption of chemicals, a decrease in discharges of chemically contaminated wastewater, which will significantly improve the state of the environment and adjacent water bodies for their use in the future. Such installations are most appropriate for newly built objects. This is especially true for hard-to-reach areas where it is difficult to transport reagents

\section{References}

1. Gromov S.L. Kriticheskie parametri obratnogo osmosa I protivotochnogo ionnogo obmena // Energosberejenie I vodopodgotovka 2004 №5. S. 13-14
2. Kopilov A.S., Lavigin V.M., Ochkov V.F. Vodopodgotovka $\mathrm{v}$ energetike. M., Izgatelstvo MEI, 2016.156 s.

3. Larin B.M. Opit osvoeniya novix texnologiy obrabotki vodi na TES // B.M. Larin, A.N. Korotkov, M.Yu. Oparin i drugie //Teploenergetika 2017. №8. S.8-13.

4. Tate J. Electrode ionization basics, Technical Pages for Ion pure Technologies, Water Technolᄀogy magazine, V. 33, № 6 - June, 2010.

5. Asretdinova M.A. Ekologichnaya texnologiya vodopodotovki na TES//Problemi energo-i resursosberejeniya 2016 №3-4. S. 55-59 